\begin{tabular}{|c|c|}
\hline \multirow{3}{*}{ 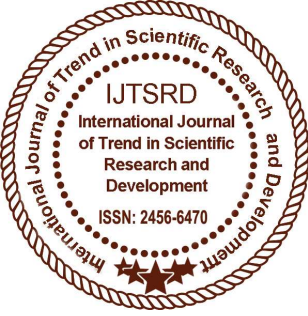 } & $\begin{array}{l}\text { International Journal of Trend in Scientific } \\
\text { Research and Development (IJTSRD) }\end{array}$ \\
\hline & International Open Access Journal \\
\hline & ISSN No: 2456 - 6470 | www.ijtsrd.com | Volume - 2 | Issue - 4 \\
\hline
\end{tabular}

\title{
An Overview of Various Waveform Contenders Based on OFDM for 5G Communication
}

\author{
Raksha Vishnoi ${ }^{1}$, Saurabh Gaur ${ }^{2}$, Ashish Verma ${ }^{2}$ \\ ${ }^{1}$ PG Student, ${ }^{2}$ Associate Professor \\ ECE Department, M.I.T., Ujjain, Madhya Pradesh, India
}

\begin{abstract}
The rollout of fifth generation $(5 \mathrm{G})$ wireless communication technology provides high spectral efficiency, high speed, greater density of users, high capacity, pseudo outdoor communication etc. In the year 2020, the data consumption is expected to increase $30 \%$ which cannot be supported by the current technologies such as $3 \mathrm{G}$ and $4 \mathrm{G}$. The $(4 \mathrm{G})$ mobile communication uses Orthogonal Frequency Division Multiplexing (OFDM) technique in various systems like - Wi-MAX. Now as the technology is being advanced to $5 \mathrm{G}$, there are some drawbacks of OFDM like - peak to average power ratio (PAPR), out of band emissions (OOB), and use of cyclic prefix (CP).In this paper, the drawbacks of Ofdm in Lte has been removed using the waveforms contenders like UFMC, FBMC, and GFDM overwhelmingly welcomed for the $5 \mathrm{G}$ air interface. The major applications of $5 \mathrm{G}$ are Internet of Things (IoT), Vehicle to Vehicle (V2V) communication, Machine to Any (M2X) communication.
\end{abstract}

Keywords: OFDM, CP, FBMC, UFMC, OOB, GFDM and F-OFDM.

\section{INTRODUCTION}

The fourth generation of cellular networks (4G), Long Term Evolution (LTE), provides high data bandwidth to strictly synchronized devices like tablets and smart phones. In the near future, it is expected that the mobile internet will massively be used for machine tomachine communications, introducing the concept of Internet-of-Things (IoT). In addition to a growing number of human-driven devices like smart phones with increasing data rates, the future fifth generation (5G) cellular networks will thus have to deal with Machine Type Communications(MTC) support users with high data rates but also a huge number of machine subscribers for which it must offer communications with low latency and be energy efficient .In the year 2020, the fifth generation mobile communication will be deployed in many countries which aim to furnish a real wireless world free from present obstacles in communication system[1].

\section{5G Technology}

Since 1980 when first generation system was introduced and till now there is seen a rapid growth in the field of communication and mobile technology. With every passing decade, the mobile generation is changing and as the current generation is $4 \mathrm{G}$ introduced in early 2010 . The year 2020 is said to be the year for the fifth generation $(5 \mathrm{G})$ systems which is smarter and sophisticated technology [1]. The 5G wireless broadband technology is actually based on IEEE 802.11 ac standard. The $5 \mathrm{G}$ is said to offer speed of $1 \mathrm{Gbps}$ and provides an end to end fully connected society

Some of the technical requirement of $5 \mathrm{G}$ is given below [2] :

1. Thousands time higher mobile data as compared to $4 \mathrm{G}$.

2. User data-rate greater than $1 \mathrm{Gbps}$.

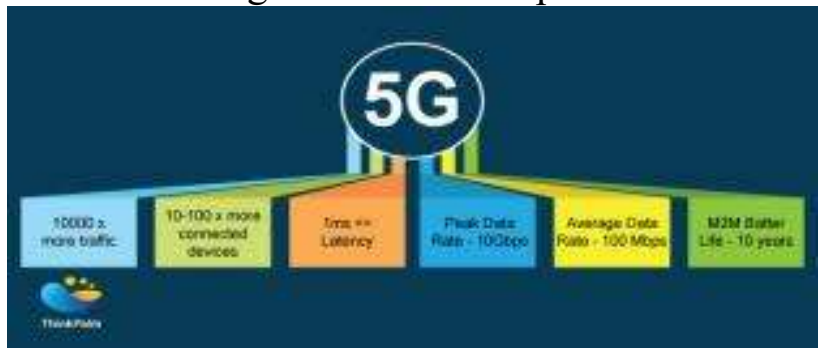

Fig 1: 5G Requirements. 
3. Ten to hundred times numbers of connected devices ascompared to $4 \mathrm{G}$.

4. More battery life.

5. Five times reduced latency as compared to $4 \mathrm{G}$.

6. 1000× higher mobile data volume per geographical area

7. $5 \mathrm{G}$ access in low populated density areas.

Now all these characteristics are not possible to achieve with the OFDM technique, hence the need for new waveform contenders isrequired [3].The special features of $5 \mathrm{G}$ when compared to $4 \mathrm{G}$ are IoT(Internet of Things), M2X communications, Tactile Internet, WRAN (Wireless Regional Area Network) and Very large data rate wireless connectivity (upto $10 \mathrm{~Gb} / \mathrm{s}$ ). These applications cannot be satisfied by OFDM technique. Hence there is a need of new techniques like- UFMC \& FOFDM,GFDM etc..

\section{Features of 5G}

1. Fast Network: The user data-rate of $4 \mathrm{G}$ is 100 Mbps but in the year 2020 will experience a data rate greater or equal to $1 \mathrm{gbps}$.

2. Reliable service in crowd areas: $5 \mathrm{G}$ aimed to give a better service and connectivity in crowd place such as shopping malls, metro station etc.

3. Service in Remote Place: Some of the application for remote place includes remote meter reading for billing purpose, e-healthlike telemedicine, smart city, and video surveillance[2].

4. Integration of numbers of low power devices: Hence 5G aimed to supports huge number devices consuming low power andsuch devices will be seamlessly integrated into commercial $5 \mathrm{G}$ mobile.

5. Intelligent Handover: $5 \mathrm{G}$, an intelligent handover is expected with the least delay during the switching of the network.

6. Pseudo Outdoor Communication: Research has proved next generation mobile communication system is aimed at pseudooutdoor communication where network coverage, data rate, and other services in the indoor area are equivalent to the outdoorarea.

7. Utilization of White Spectrum: White band utilization should be one of the important aims of $5 \mathrm{G}$ because at present white bandspectrum is unutilized and its utilization solves the issue of spectrum crisis in maximum possible extent[2],[3].

8. High Capacity: In the year 2020, consumption in wireless traffic is expected to increase by $30 \%$ hence $5 \mathrm{G}$ network shouldaccommodate the increasing numbers of users with the best quality of service.

\section{OFDM}

Orthogonal frequency division multiplexing (OFDM) is a widely used modulation and multiplexingtechnology, which has become the basis of many telecommunications standards including wireless local areanetworks (LANs), digital terrestrial television (DTT) and digital radio broadcasting in the world [4]. It is a multicarrier transmission scheme which divides the bandwidth into different subchannels known as sub-carriers so as to multiplex in both time and frequency domain. In OFDM the subcarriers are spaced at $\Delta f=1 /$ TSymbol which is known as orthogonality. In digital communications, information is expressed in the form of bits. The term symbol refers to acollection, in various sizes, of bits . OFDM data are generated by taking symbols in the spectral spaceusing M-PSK, QAM, etc, and convert the spectra to time domain by taking the Inverse Discrete FourierTransform (IDFT). Since Inverse Fast Fourier Transform (IFFT) is more cost effective to implement. It is basically a multi-carrier modulation techniquein which FDM (frequency division multiplexing) is implemented to map and transmit data over the channel [5]. The symbol duration increases because of low rate parallel sub-carriers and thus diminishes the effect of multipath delay spread.

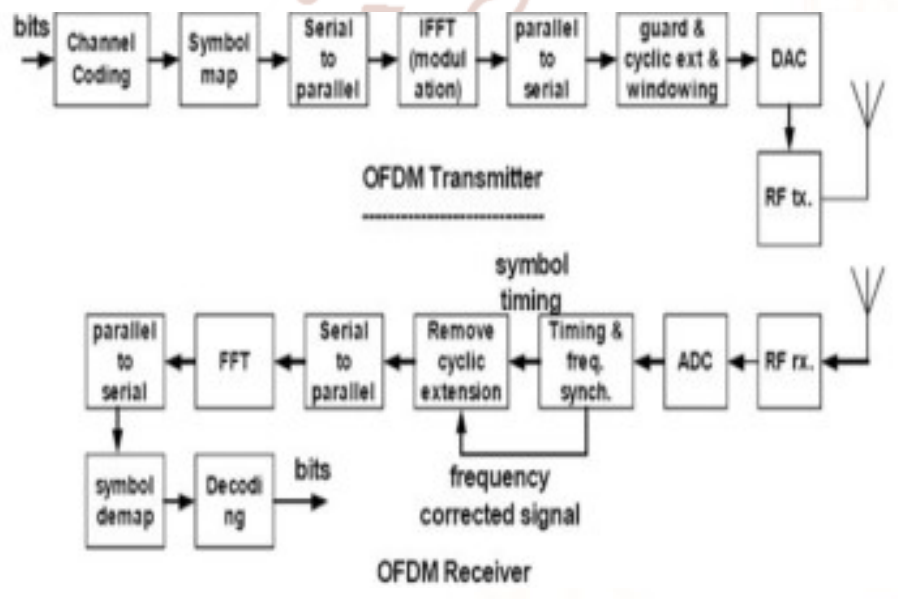

Fig 2: OFDM Transceiver Diagram[2]

In OFDM each subcarrier should be orthogonal to other subcarriers present inthe data so that the effect of inter-symbol interference is reduced. 


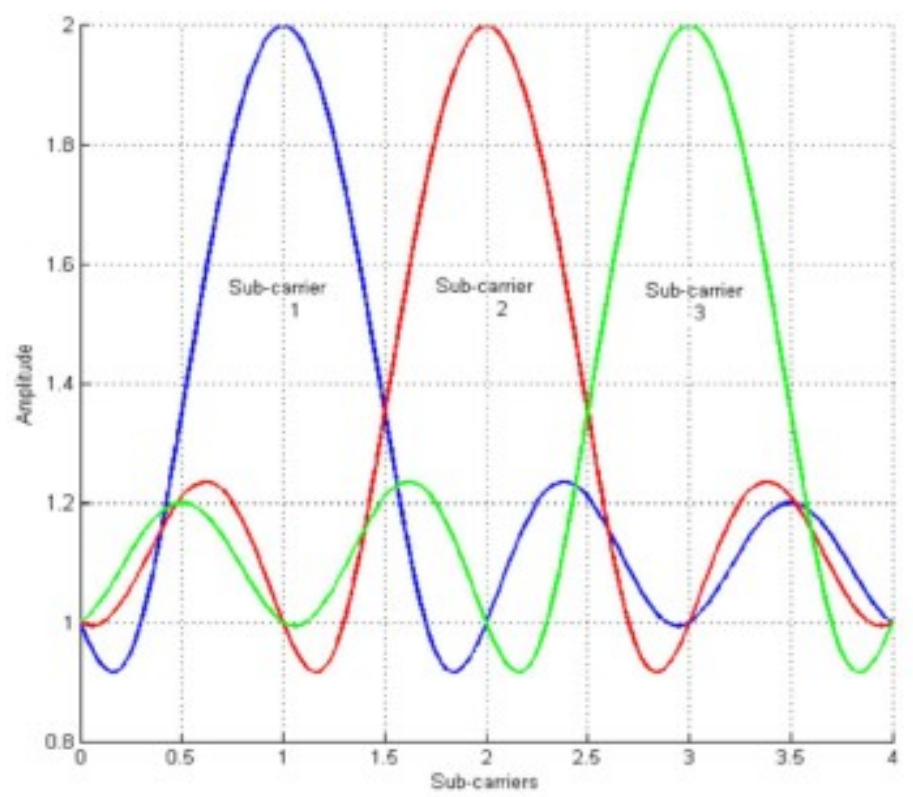

Fig 3: Orthogonality among three subcarriers

\section{4G and OFDM}

Being more specific on issues related to $4 \mathrm{G}$ networks, let us try to explain the choice of OFDM as the base technology of the current cellular communication systems [5], [6]. Between 2002 and 2004 the International Telecommunication Union (ITU), and the 3rd Generation Partnership Project (3GPP) was the technology used in the upcoming networks. Latter 3G CDMA-based systems were starting to experience problems on allowing further technological progress towards the predicted transmission rates for the coming years . In fact, in 2010 (year in which $4 \mathrm{G}$ was launched) CDMA2000 (3G) obtained by intensive manipulations, and probably by stressing the limits of this technology, downlink data transmission rates of 14.7 Mbit/s. CDMA exhibits "acceptable" speeds, and supports almost perfectly multiuser and simultaneous communications, several drawbacks exist [3],[7] .Moreover, by then, OFDM systems showed a better response compared to typical broadcast cellular technologies, and its transmission rates were significantly higher than those obtained with CDMA. But unfortunately this technology did not have the valuable multiple access feature. Therefore, while this latter problem was not solved, the consolidation of OFDM as the preferred technology for 4G networks would remain doubtful. The great solution to the above issue arrived around the year 2005 with the birth of orthogonal frequency division multiple access (OFDMA).This technology presents a performance that surpasses CDMA and other traditional multiple access technologies, such as TDMA) or FDMA, not only in terms of browsing speeds, but also by maintaining the ability of almost perfectly dealing with multipath fading channels. The next generation wireless system offers $1 \mathrm{~GB}$ speed i.e. 5G technology. OFDMA was considered as the technology to be used in the downlink of $4 \mathrm{G}$ networks, whereas singlecarrier frequency-division multiple access (SCFDMA) in the uplink. The next generation wireless system offers $1 \mathrm{~GB}$ speed i.e. 5G technology. OFDMA was considered as the technology to be used in the downlink of $4 \mathrm{G}$ networks, whereas single-carrier frequency-division multiple access(SC-FDMA) in the uplink. For the first time in history, different technologies are used in the upstream and downstream data link with the base station. SCFDMA also bases its operation on OFDM , but unlike OFDMA, it uses an extra DFT digital block, which enables each of the subcarriers to be modulated by the same data point in a short duration of time. It allows the generated signal to have a smaller PAPR in comparison with the one obtained by OFDMA [8].

Fig 4: Frequency division multiplexing (FDM)

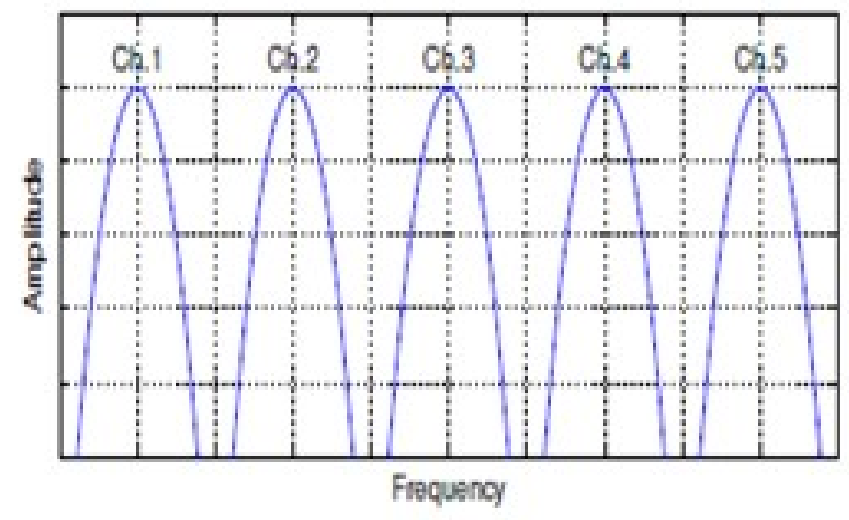

spectral representation [3].

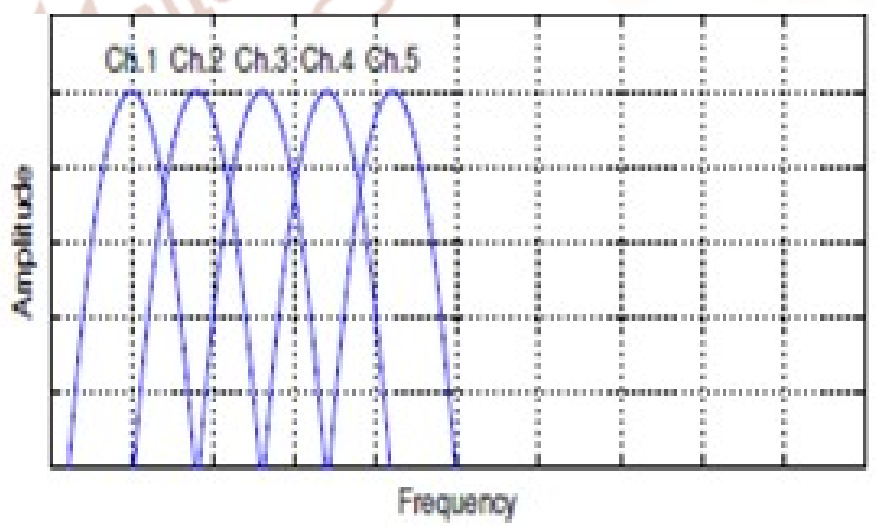

Fig 5: OFDM spectral representation [3]. 


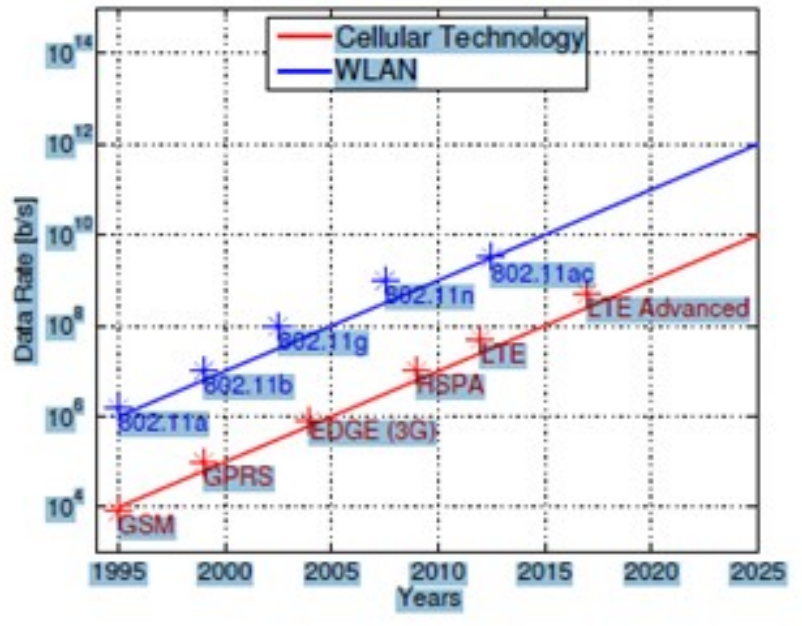

Fig 6: Data rate trend for Cellular and WLAN technologies.

\section{Key Technologies in 5G}

Generally OFDM is used as the access technique in all the network technologies like $3 \mathrm{G}$ and $4 \mathrm{G}$. But due to the basic disadvantages or limitations of OFDM, it is not used in $5 \mathrm{G}$ technology as it cannot fulfil the demands of $5 \mathrm{G}$. So different pulse shaping schemes have been used for $5 \mathrm{G}$ signals other than the conventional OFDM. Since the thansmission bandwidth is much larger than the coherence bandwidth of the channel, highly complex equalizers are needed at the receiver for accurately recovering the transmitted information. Multi-carrier techniques can solve this problem significantly [7].So different pulse shaping schemes have been used for $5 \mathrm{G}$ signals other than the conventional OFDM. The different filtering methods that are used for $5 \mathrm{G}$ will reduce the OOB emissions and will increase the spectrum efficiency. These filters will also help in reducing the Inter Carrier Interference (ICI). These techniques are UFMC,F-OFDM,GFDM,FBMC etc.

\section{A. UFMC (Universal Filter Multicarrier)}

UFMC is based on a filter bank multi carrier. In this technique a filtering operation is performed on a group of sub-carriers unlike FBMC where filtering is applied to each subcarriers. It helps in avoiding the aliasing effect. The technique efficiently reduces the side lobe which increases the performance of the system. It is usually for short burst communication. In this technique, the bandwidth is divided into numbers of sub bands and is allocated to the number of subcarriers. At the transmitter N-point IFFT operation is performed which converts the time domain of the signal to a frequency domain. At receiver, FFT is performed which converts frequency domain to a time domain [9].

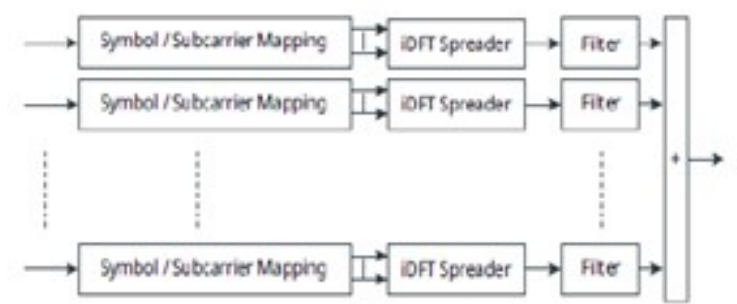

Fig 7: Modulation block of UFMC[6]

\section{B. F-OFDM (Filtered OFDM)}

In f-OFDM the available bandwidth is divided in several sub-bands, each one having different numerology and accommodating different kind of services. This is a key feature to enable flexibility of the physical layer, which is a basic requirement for the $(5 \mathrm{G})$. Even though OFDM is considered to be spectrum efficient, still $10 \%$ of allocated BW is wasted to allow attenuation of the signal .To achieve orthogonality both in frequency and time in OFDM, extra signalling to assure synchronization is needed, especially for uplink transmission. In this way, we brake intentionally the time-domain orthogonality between consecutive f-OFDM symbols for lower OOBE. Consequently, asynchronous transmission between sub-band is now supported by f-OFDM [10].

\section{Filter Bank Multicarrier (FBMC)}

It is a highly developed technique of OFDM which does not employ CP but uses arrays of filters at source and destination. Filter bank multicarrier applies filtering on a per-subcarrier foundation and is reckoned as an attractive substitute to OFDM to present an improved out-of-band spectrum characteristic. The plus point of this technique is that without using the $\mathrm{CP}$, it can give an efficient and better performance than conventional OFDM. With such attributes, it is considered as one of the most capable modulation technique for $5 \mathrm{G}$. This technique employs a bank of filters and the data in parallel pass through each filter. In FMBC offset-QAM is applied to comply with the factual orthogonality rule with the result FBMC exhibits non-orthogonality in the complex domain. OFDMwith offset Quadrature amplitude modulation (OFDM/OQAM) is the most common FBMC technique [8], [9].

\section{Generalized Frequency Division Multiplexing (GFDM)}

It is a block based non-orthogonal multicarrier transmission in nature. This scheme spreads data across two dimensions namely time and frequency. In this technique, transmission is achieved by using a 
time and frequency localized pulse and the modulation is based on a Balian low theorem. GFDM can achieve higher spectral efficiency because of the fact that it doesn't require guard band and thus avoids adjacent channel interference (ACI). In this technique, a filtering is used for each subcarrier which reduces the side lobe, PAPR, etc.

\section{Spectrum Allocation For 5G}

Federal Communication Commission (FCC) has listed some band that can be licensed for $5 \mathrm{G}$ are as follows [11]:

1. $24 \mathrm{GHz}$ Bands: $24.25-24.45 \mathrm{GHz}$ and $25.05-$
2. LMDS Bands: $27.5-28.35 \mathrm{GHz}, 29.1-29.25 \mathrm{GHz}$ and $31-31.3 \mathrm{GHz}$.

3. $39 \mathrm{GHz}$ Band: $38.64-40 \mathrm{GHz}$.

4. $37 / 42 \mathrm{GHz}: 37-38.6 \mathrm{GHz}, 42-2.5 \mathrm{GHz}$.

5. $60 \mathrm{GHz}$ band: $57-64 \mathrm{GHz}$ and $64-711 \mathrm{GHz}$.

6. $70 / 80 \mathrm{GHz}: 71-76 \mathrm{GHz}, 81-86 \mathrm{GHz}$ and $92-95$ $\mathrm{GHz}$.

\section{Comparison}

In order to have the clear vision of various techniques and technologies, its good have a comparison on the basis of performance and specifications [10].

\section{$25.25 \mathrm{GHz}$.}

Table 1 : Comparison Table between $4 \mathrm{G}$ and 5G

\begin{tabular}{|c|c|c|c|c|c|}
\hline $\begin{array}{c}\text { Generation } \rightarrow \\
\text { Features } \downarrow\end{array}$ & $1 G$ & $2 \mathrm{G}$ & $3 G$ & $4 G$ & $5 \mathrm{G}$ \\
\hline Deployment & $1970-1980$ & $1990-2001$ & $2001-2010$ & 2011 & $2015-20$ onwards \\
\hline Data Rates & $2 \mathrm{kbps}$ & $14.4-64 \mathrm{kbps}$ & $2 \mathrm{Mbps}$ & $\begin{array}{c}200 \text { Mbps to } 1 \\
\text { Gbps }\end{array}$ & $1 \mathrm{Gbps}$ and higher \\
\hline Technology & $\begin{array}{c}\text { Analog Cellular } \\
\text { Technology }\end{array}$ & $\begin{array}{c}\text { Digital Cellular Technology: } \\
\text { Digital narrow band } \\
\text { circuit data } \\
\text { Packet data }\end{array}$ & $\begin{array}{l}\text { Digital Broadband } \\
\text { Packet data: } \\
\text { CDMA 2000 } \\
\text { EVDO } \\
\text { UMTS } \\
\text { EDGE }\end{array}$ & $\begin{array}{c}\text { Digital } \\
\text { Broadband } \\
\text { Packet data: } \\
\text { WiMax LTE } \\
\text { Wi-Fi }\end{array}$ & $\begin{array}{l}\text { wwww Unified IP } \\
\text { seamless } \\
\text { combination of } \\
\text { broadband } \\
\text { LAN } \\
\text { PAN } \\
\text { MAN } \\
\text { WLAN }\end{array}$ \\
\hline Service & $\begin{array}{l}\text { Analog voice } \\
\text { service } \\
\text { No data service }\end{array}$ & $\begin{array}{l}\text { Digital voice with higher clanity } \\
\text { SMS, MMS } \\
\text { Higher capacity packetized data }\end{array}$ & $\begin{array}{c}\text { Enhanced audo video } \\
\text { streaming } \\
\text { video conferencing } \\
\text { support } \\
\text { Web browsing at } \\
\text { higher speeds } \\
\text { IPTV support }\end{array}$ & $\begin{array}{l}\text { Enhanced } \\
\text { audio, video } \\
\text { streaming } \\
\text { IP telephony } \\
\text { HD mobile TV }\end{array}$ & $\begin{array}{c}\text { Dynamic } \\
\text { Information } \\
\text { access, } \\
\text { Wearable devices } \\
\text { with AI } \\
\text { Capabilities }\end{array}$ \\
\hline $\begin{array}{l}\text { Multiplexing } \\
\text { Switching }\end{array}$ & FDMA & TDMA, CDMA & CDMA & CDMA & CDMA \\
\hline Core Network & PSTN & PSTN & Packet N/W & Intemet & Intemet \\
\hline Standards & $\begin{array}{l}\text { MTS } \\
\text { AMTS } \\
\text { IMTS }\end{array}$ & $\begin{array}{c}\text { 2G:GSM } \\
\text { 2.5:GPRS } \\
\text { 2.75:EDGE }\end{array}$ & $\begin{array}{c}\text { IMT-2000 } \\
\text { 3.5G-HSDPA } \\
\text { 3.75G:HSUPA }\end{array}$ & $\begin{array}{l}\text { Single unified } \\
\text { standard } \\
\text { LTE, } \\
\text { WLMAX }\end{array}$ & $\begin{array}{l}\text { Single unified } \\
\text { standard }\end{array}$ \\
\hline WEB Standard & & www & www(IPv4) & www (IPv4) & wwww (IPv6) \\
\hline Handoff & Horizontal only & Horizontal only & Horizontal \& Vertical & $\begin{array}{c}\text { Horizontal \& } \\
\text { Vertical }\end{array}$ & $\begin{array}{c}\text { Honizontal \& } \\
\text { Vertical }\end{array}$ \\
\hline Shortfalls & $\begin{array}{c}\text { Low capacity, } \\
\text { Unreliable handoff, } \\
\text { Poor voice links, Less } \\
\text { secure }\end{array}$ & $\begin{array}{c}\text { Digital signals were reliant on } \\
\text { location \& proximity, required } \\
\text { strong digtal signals to help } \\
\text { mobile phones }\end{array}$ & $\begin{array}{l}\text { Need to accommodate } \\
\text { higher network } \\
\text { capacity }\end{array}$ & Being deployed & $\begin{array}{l}\text { Yet to be } \\
\text { implemented }\end{array}$ \\
\hline
\end{tabular}

\section{Conclusion}

The present work gives the comprehensive study of $5 \mathrm{G}$ indicating the key technologies, current development in $5 \mathrm{G}$, requirements of future wireless communication and previews different techniques proposed for future $5 \mathrm{G}$ networks. As the data rate is becoming higher in the future generation networks there is a migration from existing network to IP-based networks that takes place on the network layer. Basically, the main aim of $5 \mathrm{G}$ was to make a real wireless world free from present obstacles and provide reliable service with more functionality to end nodes. This is only possible if all the existed radio technologies and future technologies were integrated with 5G. Overall, the year 2020 will bring a revolutionary change in the field of Communication system where everybody is connected from anywhere, at any time.

\section{$X$. References}

1. G. Hill, M. Faulkner, and J. Singh, "Reducing the peak-to-average power ratio in OFDM by cyclically shifting partial transmit sequences," 
Electronics Letters, vol. 36, pp. 560-561, Mar 16 2000.

2. 5g Radio Access Ericsson White Paper, 2013.

3. Shanzhi Chen, Jian Zhao, The requirements, challenges, and technologies for $5 \mathrm{G}$ of terrestrial mobile telecommunication, IEEE Commun. Mag. $52(5)(2014) 36-43$.

4. J. Thompson, X. Ge, H.C. Wu, R. Irmer, H. Jiang, G. Fettweis, S. Alamouti, 5G wireless communication systems: prospects and challenges, IEEE Commun. Mag. 52 (2) (2014)

5. Performance of emerging multi-carrier waveforms for $5 \mathrm{G}$ asynchronous communications Mathieu Van Eeckhaute1,Andre Bourdoux2, Philippe De Doncker1 and Francois Horlin1.

6. Ijaz, A., et al. Enabling massive IoT in $5 \mathrm{G}$ and beyond systems: PHY radio frame design considerations. IEEE Access. 2016; 4:3322-3339.
7. "5G WIRELESS TECHNOLOGY" by Ganesh R. Patil, Prof. Prashant S. Wankhade in IJCSMC, Vol. 3, Issue. 10, October 2014, IJCSMC, Vol. 3, Issue. 10, October 2014.

8. ICT-317669 METIS Project, Scenarios, Requirement, and KPIs for 5G Mobile and wireless communication ,www.mettis.2020document.com

9. X Zhang, L Chen, J Qiu, J Abdoli, On the waveform for 5G. IEEE Commun. Mag. 54(11), (2016).doi:10.1109/MCOM.2016.1600337CM.

10. Z Wang, GB Giannakis, Wireless Multicarrier Communications. IEEE Signal Process Mag. 17(3), 29-48 (2000). doi:10.1109/79.841722

11. JG Andrews, S Buzzi, W Choi, SV Hanly, A Lozano, ACK Soong, JC Zhang, What will 5G be? IEEE J. Sel. Areas Commun. 32(6), 10651082 (2014).doi:10.1109/JSAC.2014.2328098

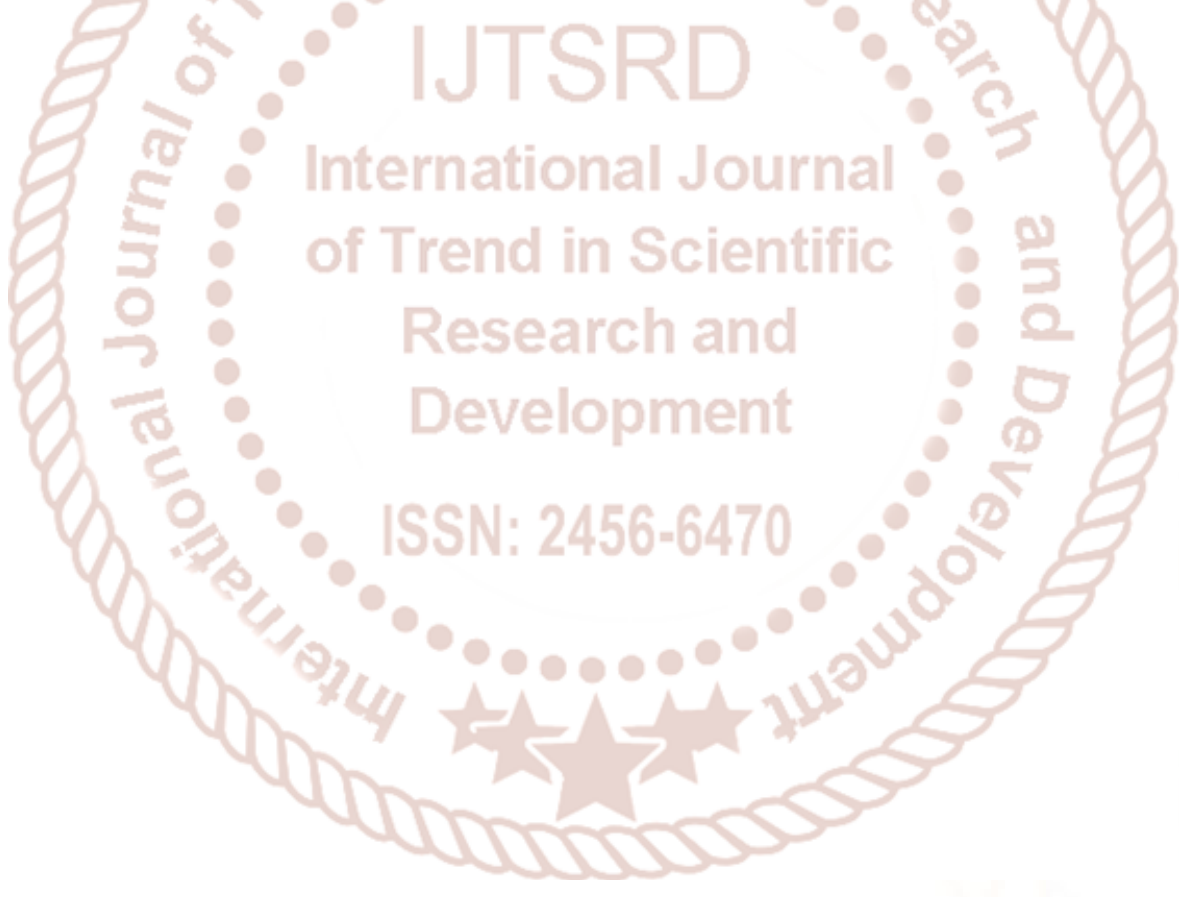

